\title{
Analisis Efektivitas Biaya Penggunaan Kontrasepsi di Indonesia Tahun 2014-2017
}

\author{
Shahnaz D. Khoiriyah ${ }^{1}$, Neily Zakiyah ${ }^{2}$, Auliya A. Suwantika ${ }^{2}$ \\ ${ }^{1}$ Fakultas Farmasi, Universitas Padjadjaran, Sumedang, Indonesia, \\ ${ }^{2}$ Departemen Farmakologi dan Farmasi Klinik, Fakultas Farmasi, \\ Universitas Padjadjaran, Sumedang, Indonesia
}

\begin{abstract}
Abstrak
Keluarga berencana menjadi salah satu program kesehatan dan kependudukan di Indonesia yang pembiayaannya dijamin oleh sistem Jaminan Kesehatan Nasional (JKN). Tujuan penelitian ini adalah mengetahui analisis efektivitas biaya penggunaan kontrasepsi hormonal dan nonhormonal di Indonesia pada tahun 2014-2017. Penelitian ini merupakan penelitian kuantitatif menggunakan data sekunder dengan pengambilan data dilakukan secara retrospektif, dan dilaksanakan di Fakultas Farmasi Universitas Padjadjaran pada bulan Oktober 2018 hingga Januari 2019. Metode yang digunakan pada penelitian ini adalah analisis efektivitas biaya dengan menghitung Incremental Cost-effectiveness Ratio (ICER). Perspektif biaya yang digunakan adalah payer perspective (BPJS Kesehatan). Hasil penelitian menunjukkan bahwa beban biaya penggunaan kontrasepsi hormonal pada tahun 2014-2017 di Indonesia memiliki nilai yang lebih rendah dibandingkan beban biaya penggunaan kontrasepsi nonhormonal. Dari segi efektivitas, kontrasepsi nonhormonal memiliki efektivitas yang lebih rendah dibandingkan efektivitas hormonal. Simpulan penelitian ini adalah kontrasepsi hormonal lebih cost-effective dengan nilai ICER kontrasepsi hormonal sebesar Rp64.471/ 1\% kehamilan yang dapat dicegah sedangkan nilai ICER kontrasepsi nonhormonal sebesar Rp341.003/1\% kehamilan yang dapat dicegah. Analisis sensitivitas menunjukkan bahwa efektivitas metode kontrasepsi menjadi faktor paling berpengaruh terhadap nilai ICER.
\end{abstract}

Kata kunci: Analisis sensitivitas, incremental cost-effectiveness ratio (ICER), kontrasepsi hormonal dan nonhormonal

\section{Cost-effectiveness Analysis of Contraceptive Use in Indonesia during 2014-2017}

\begin{abstract}
Family planning is one of the healthcare programs in Indonesia that is included in the National Health Insurance (NHI) system. The purpose of this study was to determine the cost-effectiveness analysis of hormonal and non-hormonal contraceptive use in Indonesia during 2014-2017. A quantitative study was applied in this study and data collection was collected retrospectively. This study was conducted at the Faculty of Pharmacy, Universitas Padjadjaran from October 2018 to January 2019. A cost-effectiveness analysis was applied by calculating the Incremental Cost-effectiveness Ratio (ICER). A payer perspective was considered by calculating all costs covered by BPJS Kesehatan. The results showed that the cost of using hormonal contraception during 2014-2017 in Indonesia was lower than non-hormonal contraception. In term of effectiveness, non-hormonal contraception had a lower effectiveness compared to hormonal effectiveness. It can be concluded that hormonal contraception was more cost-effective than non-hormonal contraception by confirming that ICER of hormonal contraception $(64,471$ IDR $/ 1 \%$ pregnancy averted) was lower than non-hormonal contraception $(341,003 \mathrm{IDR} / 1 \%$ pregnancy averted). Sensitivity analysis confirmed that effectiveness of contraception method is the most critical factor affecting the ICER value.
\end{abstract}

Keywords: Hormonal and non-hormonal contraception, incremental cost-effectiveness ratio (ICER), sensitivity analysis

\footnotetext{
Korespondensi: Auliya A. Suwantika, Ph.D., Apt., Departemen Farmakologi dan Farmasi Klinik, Fakultas Farmasi, Universitas Padjadjaran, Sumedang, Jawa Barat 45363, Indonesia, email: auliya@unpad.ac.id

Naskah diterima: 25 Februari 2019, Diterima untuk diterbitkan: 27 Agustus 2019, Diterbitkan: 28 September 2019
} 


\section{Pendahuluan}

Program Keluarga Berencana (KB) adalah sebuah program kesehatan dan kependudukan yang bertujuan untuk mengatur kehamilan, kelahiran, serta jarak dan usia ideal untuk melahirkan. Pengaturan kehamilan dalam program KB dilakukan dengan penggunaan kontrasepsi ${ }^{1}$ yang dikelompokkan ke dalam dua metode, antara lain hormonal (pil, suntik, implan) dan nonhormonal (metode operasi, intrauterine device/IUD, barrier methods). ${ }^{2}$

Program Jaminan Kesehatan Nasional (JKN) resmi dilaksanakan sejak 1 Januari $2014,{ }^{1}$ dan evaluasi pelaksanaan JKN terus dilakukan untuk memperbaiki kekurangan yang terdapat pada program ini. Evaluasi dapat dilakukan dengan berbagai pendekatan, salah satunya melalui pendekatan economic analysis yang memberikan informasi kepada pembuat kebijakan mengenai nilai dari suatu alternatif pengobatan untuk menentukan prioritas intervensi dengan mempertimbangkan sumber daya secara efisien. ${ }^{3}$

Program KB menjadi salah satu program nasional di Indonesia yang telah dilaksanakan sejak tahun 1970 sampai saat ini, dan program ini memiliki peranan penting dalam menekan angka kelahiran di Indonesia. Pelayanan KB menjadi salah satu dari pelayanan kesehatan yang dijamin oleh JKN dan pembiayaannya diatur dalam Permenkes No. 59 tahun 2014. ${ }^{1}$ Kontrasepsi yang merupakan bagian dari program KB menjadi salah satu bagian dari JKN yang perlu dilakukan evaluasi dengan pendekatan economic analysis mengingat pembiayaannya mengalami perubahan sejak era JKN. Evaluasi yang dilakukan tidak hanya melibatkan aspek biaya saja, namun juga aspek efektivitas. Evaluasi ini dapat dilakukan dengan cara menggunakan salah satu kajian farmakoekonomi yaitu analisis efektivitas biaya. Analisis efektivitas biaya dilakukan untuk mengevaluasi biaya dan efektivitas dari dua atau lebih intervensi yang memberikan outcome yang berbeda dan digunakan untuk memilih intervensi yang terbaik dari beberapa pilihan intervensi. ${ }^{4}$ Analisis efektivitas biaya dari penggunaan kontrasepsi setelah adanya JKN dapat memberikan informasi mengenai metode kontrasepsi yang paling cost-effective pada era JKN. Penelitian ini bertujuan untuk mengetahui beban biaya, analisis efektivitas biaya dan faktor yang paling memengaruhi Incremental Cost-effectiveness Ratio (ICER) dari penggunaan kontrasepsi hormonal dan nonhormonal di Indonesia pada tahun 20142017 (era JKN).

\section{Metode}

Penelitian ini dilaksanakan pada Oktober 2018-Januari 2019 dan telah mendapatkan izin etik dari Komisi Etik Penelitian Fakultas Kedokteran Universitas Padjadjaran No. 293/ UN6.KEP/EC/2019. Kriteria inklusi penelitian ini adalah data penggunaan kontrasepsi aktif di Indonesia pada tahun 2014-2017, sedangkan kriteria eksklusi penelitian ini adalah data pengguna kontrasepsi aktif dengan data yang tidak lengkap dan tidak dapat ditelusuri.

Pengambilan data penelitian ini dilakukan secara retrospektif menggunakan data sekunder. Data yang dimaksud adalah: 1) Data jumlah pengguna $\mathrm{KB}$ aktif di Indonesia berdasarkan metode kontrasepsi yang diperoleh dari Profil Kesehatan Indonesia tahun 2014-2017; 2) Data efektivitas kontrasepsi yang diperoleh dari Diagram Lingkaran Kriteria Kelayakan Medis dalam Penggunaan Kontrasepsi World Health Organization (WHO) edisi 2 tahun 2017. Efektivitas yang dimaksud merupakan persentase dari angka kehamilan yang dapat dicegah oleh setiap metode kontrasepsi; 3) Data mengenai biaya penggunaan KB yang diperoleh dari Peraturan Menteri Kesehatan Republik Indonesia No. 59 tahun 2014 tentang Standar Tarif Pelayanan Kesehatan dalam Penyelenggaraan Program Jaminan Kesehatan, INA-CBG yang dikeluarkan oleh 
Kemeterian Kesehatan Republik Indonesia tahun 2016 dan Keputusan Menteri Kesehatan Republik Indonesia No. 1079/MENKES/SK/ VIII/2010 tentang Harga Obat Kontrasepsi dan Alat Kontrasepsi Tahun 2010.

Pada penelitian ini, metode kontrasepsi dibagi menjadi kontrasepsi hormonal yaitu implan, suntik, serta pil, dan kontrasepsi nonhormonal yaitu IUD, Metode Operasi Wanita (MOW), Metode Operasi Pria (MOP), serta kondom. Peserta KB aktif merupakan Pasangan Usia Subur (PUS) yang sedang menggunakan kontrasepsi tanpa diselingi dengan kehamilan. PUS sendiri merupakan pasangan suami-istri yang berada dalam pernikahan yang sah dengan usia istri berada pada rentang 15-49 tahun. ${ }^{5}$

Beban biaya dari penggunaan kontrasepsi dihitung dengan rumus berikut:

Beban biaya $=\frac{\sum \text { Jumlah pengguna kontrasepsi } \times \text { Biaya penggunaan metode kontrasepsi }}{\text { Total jumbh }}$

Beban biaya selanjutnya dilakukan discounting dengan faktor discounting sebesar 3\% setiap tahunnya. ${ }^{6}$

Perspektif pada penelitian ini adalah payer perspective, yaitu BPJS Kesehatan. Beban biaya yang dimaksud merupakan besaran biaya langsung medik yang harus ditanggung oleh BPJS Kesehatan. Analisis efektivitas biaya diperoleh berdasarkan perbandingan nilai ICER antara penggunaan kontrasepsi hormonal dan nonhormonal. ICER merupakan selisih biaya pemberian suatu intervensi dan tanpa adanya intervensi dibagi dengan selisih efektivitas pemberian suatu intervensi dan tanpa adanya intervensi. ${ }^{7}$ Nilai ICER didapat dengan rumus berikut:

$\mathrm{ICER}=\frac{\text { Beban biaya dengan kontrasepsi }- \text { Beban biaya tanpa kontrasepsi }}{\text { Efektivitas kontrasepsi }- \text { Efektivitas tanpa kontrasepsi }}$

Analisis sensitivitas digunakan untuk mengetahui faktor yang memengaruhi ICER dan untuk mengatasi ketidakpastian yang terjadi pada saat perhitungan ICER. Contoh ketidakpastian yang mungkin terjadi seperti adanya kenaikan atau penurunan harga dan/ atau efektivitas dari kontrasepsi. Hasil dari analisis sensitivitas disajikan dalam diagram tornado. ${ }^{8}$ Analisis sensitivitas dilakukan dengan memvariasikan biaya dan efektivitas. ${ }^{9}$ Pada penelitian ini, analisis sensitivitas dilakukan dengan mengubah nilai salah satu variabel biaya dan efektivitas dalam kisaran $\pm 25 \% .{ }^{10}$ Jika salah satu variabel mengalami pengubahan nilai, maka nilai dari varibel lain harus dalam keadaan tetap. ${ }^{11}$

\section{Hasil}

Kontrasepsi hormonal merupakan metode kontrasepsi yang paling banyak digunakan setiap tahun. Pada periode tahun 2014-2016, persentase pengguna kontrasepsi hormonal mencapai $82 \%$ setiap tahunnya dan pada tahun 2017 mencapai 88\%, sedangkan persentase pengguna kontrasepsi nonhormonal pada periode tahun 2014-2016 adalah sebesar $18 \%$ setiap tahunnya dan pada tahun 2017 hanya mencapai $12 \%$. Jumlah pengguna KB aktif pada tahun 2014-2017 terus mengalami kenaikan setiap tahunnya, kecuali pada tahun 2017. Penurunan jumlah pengguna KB aktif pada tahun 2017 mencapai 13.011.831 orang (Tabel 1). Metode kontrasepsi suntik menjadi metode dengan akseptor terbanyak setiap tahunnya di Indonesia.

Hasil biaya penggunaan kontrasepsi (Tabel 2) menunjukkan bahwa pada kontrasepsi hormonal, implan menjadi metode kontrasepsi paling mahal sedangkan pil menjadi metode kontrasepsi paling murah. Pada kontrasepsi nonhormonal, MOW merupakan metode kontrasepsi paling mahal sedangkan kondom menjadi metode kontrasepsi paling murah. Secara keseluruhan, metode kontrasepsi MOW merupakan kontrasepsi dengan biaya tertinggi sedangkan pil merupakan metode kontrasepsi dengan biaya terendah. Beban biaya penggunaan kontrasepsi nonhormonal tahun 2014-2017 yaitu sebesar Rp287.125/ pengguna setiap tahunnya, sedangkan beban 
Tabel 1 Pengguna KB Aktif di Indonesia Tahun 2014-2017

\begin{tabular}{lccccc}
\hline \multicolumn{1}{c}{ Jenis Kontrasepsi } & $\mathbf{2 0 1 4}$ & $\mathbf{2 0 1 5}$ & $\mathbf{2 0 1 6}$ & $\mathbf{2 0 1 7}$ & Jumlah \\
\hline IUD & 3.896 .081 & 3.840 .156 & 3.852 .561 & 1.688 .685 & 13.277 .483 \\
MOW & 1.238 .749 & 1.249 .364 & 1.285 .991 & 655.762 & 4.429 .866 \\
MOP & 241.642 & 234.206 & 233.935 & 124.262 & 834.045 \\
Kondom & 1.110 .341 & 1.131 .373 & 1.171 .509 & 288.388 & 3.701 .611 \\
Nonhormonal & 6.486 .813 & 6.455 .099 & 6.543 .996 & 2.757 .097 & 22.243 .005 \\
Implan & 3.680 .816 & 3.788 .149 & 4.067 .699 & 1.650 .227 & 13.186 .891 \\
Suntik & 16.734 .917 & 17.104 .340 & 17.414 .144 & 14.817 .663 & 66.071 .064 \\
Pil & 8.300 .362 & 8.447 .972 & 8.280 .823 & 4.069 .844 & 29.099 .001 \\
Hormonal & 28.716 .095 & 29.340 .461 & 29.762 .666 & 20.537 .734 & 108.356 .956 \\
\hline
\end{tabular}

biaya penggunaan kontrasepsi hormonal yaitu sebesar Rp54.660/pengguna setiap tahunnya (Tabel 3).

Efektivitas kontrasepsi yang ditunjukkan pada Tabel 4 merupakan hasil modifikasi dari publikasi resmi WHO tahun 2015 pada Medical Eligibility Criteria for Contraceptive Use yang telah dilakukan uji coba serta penyesuaian di Indonesia sehingga efektivitas kontrasepsi yang diperoleh telah disesuaikan dengan efektivitas kontrasepsi di Indonesia. Metode hormonal memiliki efektivitas yang lebih tinggi dibandingkan nonhormonal.

Hasil perhitungan nilai ICER penggunaan kontrasepsi tahun 2014-2017 dapat dilihat pada Tabel 5. Beban biaya tanpa penggunaan kontrasepsi adalah $\mathrm{Rp} 0$ dan efektivitas tanpa penggunaan kontrasepsi adalah $15 \%$. Nilai ICER penggunaan kontrasepsi nonhormonal adalah Rp341.003/1\% pencegahan kehamilan sedangkan nilai ICER penggunaan kontrasepsi hormonal adalah Rp64.471/1\% pencegahan kehamilan. Hasil analisis sensitivitas yang dapat dilihat pada Gambar 1 menunjukkan bahwa faktor yang memiliki pengaruh besar terhadap nilai ICER kontrasepsi hormonal dan kontrasepsi nonhormonal adalah efektivitas metode konrasepsi.

\section{Pembahasan}

Penurunan jumlah pengguna $\mathrm{KB}$ aktif tahun 2017 sejalan dengan adanya peningkatan pada jumlah PUS yang tidak menggunakan KB di tahun yang sama. Pada tahun 2016, terdapat sebanyak $12,77 \%$ PUS yang bukan merupakan peserta KB aktif, ${ }^{12}$ yang kemudian pada 2017 mengalami peningkatan menjadi $36,78 \%$ dari keseluruhan jumlah PUS di Indonesia. ${ }^{5}$ Metode kontrasepsi yang paling banyak dipakai adalah kontrasepsi suntik, hal ini disebabkan kelebihan long acting-effect yang dimiliki sehingga tidak perlu digunakan setiap hari, reversibel serta murah. ${ }^{13}$

Tabel 2 Biaya Penggunaan Kontrasepsi

\begin{tabular}{lc}
\hline \multicolumn{1}{c}{ Metode Kontrasepsi } & Biaya \\
\hline Intrauterine Device (IUD) (copper T) & Rp100.000/pemasangan \\
Metode Operasi Wanita (MOW) & Rp1.100.000/pelayanan \\
Metode Operasi Pria (MOP) & Rp350.000/pelayanan \\
Kondom & Rp61.000/gross \\
Implan (2rods levonogestrel 75 mg) & Rp100.000/pemasangan \\
Suntik (150 mg/3 ml medroksi progesteron asetat) & Rp15.000/1 kali suntik \\
Pil (30 mcg etinilestrasiol+150 mcg levonogestrel) & Rp2.175/blister \\
\hline
\end{tabular}


Tabel 3 Beban Biaya Penggunaan Kontrasepsi Nonhormonal dan Hormonal di Indonesia Tahun 2014-2017

\begin{tabular}{lcc}
\hline & Kontrasepsi Nonhormonal & Kontrasepsi Hormonal \\
\hline Biaya & Rp6.386.519.401.192 & Rp5.922.833.294.735 \\
Jumlah Pengguna & 22.243 .005 & 108.356 .956 \\
Beban Biaya & Rp287.125 & Rp54.660 \\
\hline
\end{tabular}

Biaya kontrasepsi termahal adalah MOW, Metode Kontrasepsi Jangka Panjang (MKJP) merupakan metode kontrasepsi dengan biaya yang tinggi. ${ }^{14}$ IUD menjadi MKJP paling murah dibandingkan dengan MKJP lainnya. ${ }^{15}$ Beban biaya kontrasepsi nonhormonal lebih besar dibandingkan beban biaya kontrasepsi hormonal. Hal ini terjadi karena rata-rata biaya pemakaian kontrasepsi nonhormonal lebih tinggi dibandingkan hormonal. Selain itu, pada penelitian ini terdapat 4 jenis metode kontrasepsi nonhormonal sedangkan metode hormonal hanya terdapat 3 jenis saja. Hal ini menyebabkan beban biaya metode kontrasepsi nonhormonal selalu tinggi setiap tahunnya.

Pada penelitian ini, implan menjadi metode kontrasepsi hormonal dengan efektivitas yang paling tinggi dalam mencegah kehamilan. Hal ini sesuai dengan hasil penelitian sebelumnya yang menyatakan bahwa implan menjadi salah satu metode kontrasepsi dengan efektivitas yang tinggi untuk mencegah kehamilan yang tidak direncanakan dan aborsi. ${ }^{16}$ Pada metode kontrasepsi nonhormonal, MOP merupakan metode kontrasepsi dengan efektivitas paling tinggi jika dibandingkan metode kontrasepsi nonhormonal lain. Hal ini dapat disebabkan MOP adalah kontrasepsi pria yang paling aman dan efektif. Jika dibandingkan dengan
MOW, MOP lebih mudah dilakukan, lebih cepat, serta lebih cost-effective. ${ }^{17}$ Berbanding terbalik dengan MOP, kondom merupakan kontrasepsi dengan efektivitas paling rendah. Hal ini disebabkan tingginya kesalahan dalam penggunaan kondom seperti terjadinya bocor dan slip pada kondom. ${ }^{18}$ Efektivitas kondom yang rendah merupakan penyebab efektivitas kontrasepsi nonhormonal menjadi lebih kecil dibandingkan hormonal.

Hasil akhir dari analisis efektivitas biaya dinyatakan dalam nilai ICER, yakni rasio besaran biaya yang diperlukan untuk setiap peningkatan satu unit efektivitas. ${ }^{19}$ Nilai ICER penggunaan kontrasepsi hormonal memiliki nilai yang lebih kecil jika dibandingkan nilai ICER penggunaan kontrasepsi nonhormonal. Hal ini menunjukkan bahwa kontrasepsi hormonal lebih cost-effective dibandingkan nonhormonal. Secara spesifik, Mavranezouli (2009) menyatakan bahwa metode kontrasepsi hormonal merupakan kontrasepsi paling costeffective setelah MKJP, sedangkan metode kontrasepsi nonhormonal lain selain MKJP menempati posisi paling least cost-effective. ${ }^{20}$ Nilai ICER penggunaan kontrasepsi hormonal yang rendah ini disebabkan oleh beban biaya yang lebih rendah dan efektivitas yang lebih tinggi dibandingkan beban biaya penggunaan kontrasepsi nonhormonal.

Tabel 4 Efektivitas Kontrasepsi di Indonesia

\begin{tabular}{cccccccc}
\hline \multirow{2}{*}{$\begin{array}{c}\text { Tanpa } \\
\text { Kontrasepsi (\%) }\end{array}$} & \multicolumn{3}{c}{ Kontrasepsi Nonhormonal (\%) } & \multicolumn{3}{c}{ Kontrasepsi Hormonal (\%) } \\
\cline { 2 - 8 } & IUD & MOW & MOP & Kondom & Implan & Suntik & Pil \\
\hline 15,00 & 99,40 & 99,50 & 99,90 & 98,00 & 99,95 & 99,70 & 99,70 \\
15,00 & \multicolumn{4}{c}{99,20} & & 99,78 & \\
\hline Keterangan: IUD=Intrauterine Device; MOW=Metode Operasi Wanita; MOP=Metode Operasi Pria &
\end{tabular}

Keterangan: IUD=Intrauterine Device; MOW=Metode Operasi Wanita; MOP=Metode Operasi Pria 
Tabel 5 Nilai ICER Penggunaan Kontrasepsi di Indonesia Tahun 2014-2017

\begin{tabular}{lccc}
\hline \multicolumn{1}{c}{ Metode Kontrasepsi } & Beban Biaya (Rp) & Efektivitas (\%) & ICER (Rp/\%) \\
\hline Tanpa Kontrasepsi & 0 & 15,00 & - \\
Nonhormonal & 287.125 & 99,20 & 341.003 \\
Hormonal & 54.66 & 99,78 & 64.471 \\
\hline
\end{tabular}

Analisis sensitivitas dapat memberikan gambaran nilai ICER jika terjadi peningkatan ataupun penurunan nilai pada salah satu variabel..$^{21}$ Baseline yang digunakan pada penelitian ini adalah nilai ICER dari masingmasing metode kontrasepsi (hormonal dan nonhormonal). ${ }^{9}$ Suatu intervensi dinyatakan dominan jika memiliki nilai ICER paling kecil pada lower value dan nilai ICER paling besar pada upper value..$^{22}$ Besarnya pengaruh dari setiap faktor dilihat dari besarnya range ICER lower value dengan ICER upper value. Hasil dari analisis sensitivitas menunjukkan bahwa efektivitas dari metode kontrasepsi merupakan faktor/komponen yang memiliki pengaruh paling besar, baik pada metode kontrasepsi nonhormonal maupun hormonal. Hal ini dapat menjadi pertimbangan bagi pemangku kebijakan pada saat menentukan aspek mana yang akan menjadi fokus utama dalam rangka upaya penurunan nilai ICER. Konsistensi dan ketepatan penggunaan dapat meningkatkan efektivitas dari kontrasepsi, ${ }^{23}$ sehingga pemangku kebijakan diharapkan

\section{(A) Analisis Sensitivitas Kontrasepsi Nonhormonal}

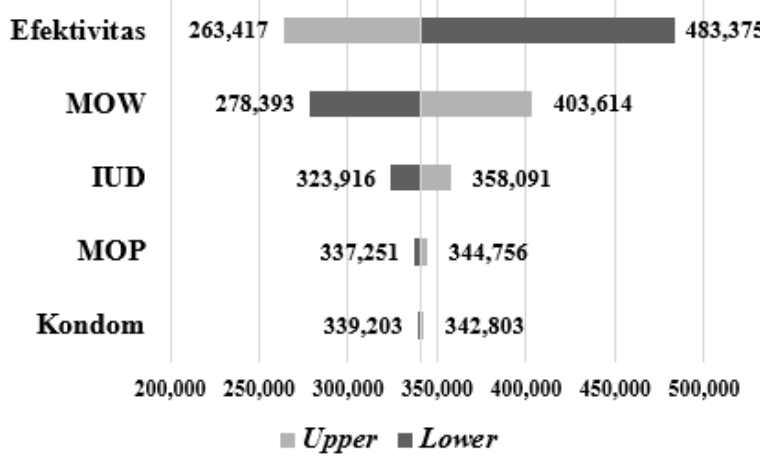

dapat terus berupaya meningkatkan efektivitas kontrasepsi dengan memperhatikan kedua aspek tersebut, dan didukung oleh peningkatan pelayanan penggunaan kontrasepsi dari tenaga medis di pelayanan kesehatan.

Cakupan penelitian ini meliputi seluruh provinsi di Indonesia, dengan jumlah pengguna kontrasepsi adalah jumlah yang sesungguhnya (real) bukan dengan sampling atau hanya pada populasi kecil, sehingga hasil pada penelitian ini dapat memberikan gambaran analisis efektivitas biaya penggunaan kontrasepsi di seluruh wilayah di Indonesia. Namun, terdapat beberapa keterbatasan pada penelitian ini, salah satunya yaitu pengelompokan metode kontrasepsi yang kurang spesifik yakni hanya sebatas kelompok kontrasepsi hormonal dan nonhormonal sehingga terjadi kesulitan pada saat dibandingkan dengan penelitian lainnya. Selain itu, hasil yang diperoleh kurang spesifik kepada setiap metode kontrasepsi. Penelitian selanjutnya dengan pengelompokan metode kontrasepsi yang lebih spesifik diharapkan dapat dilakukan di kemudian hari.
(B)

\section{Analisis Sensitivitas Kontrasepsi Hormonal}

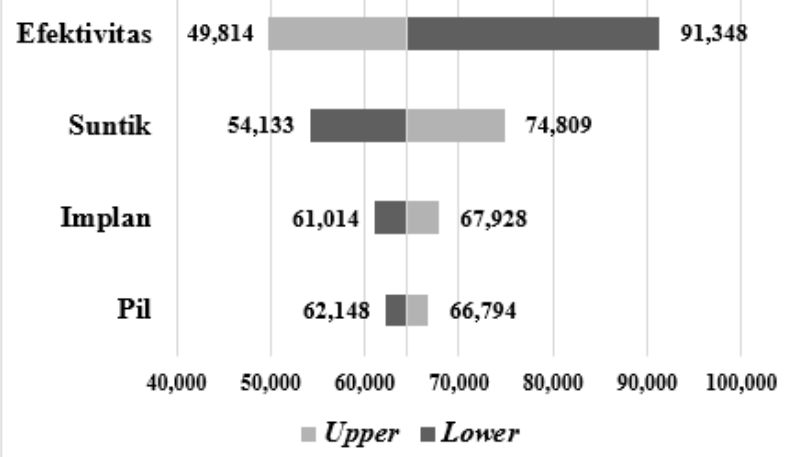

Gambar 1 Analisis Sensitivitas Biaya Penggunaan Kontrasepsi (A) Nonhormonal dan (B) Hormonal 


\section{Simpulan}

Beban biaya penggunaan kontrasepsi nonhormonal lebih tinggi jika dibandingkan kontrasepsi hormonal. Nilai ICER kontrasepsi hormonal sebesar Rp64.471/efektivitas lebih cost-effective jika dibandingkan kontrasepsi nonhormonal sebesar Rp341.003/efektivitas. Efektivitas kontrasepsi menjadi faktor yang memengaruhi perhitungan ICER. Hasil ini diharapkan dapat menjadi landasan awal bagi pemangku kebijakan dalam membuat kebijakan mengenai penggunaan kontrasepsi terutama untuk meningkatkan efektivitas kontrasepsi.

\section{Pendanaan}

Penelitian ini dilakukan tanpa bantuan/hibah dari sumber hibah manapun.

\section{Konflik Kepentingan}

Seluruh penulis menyatakan tidak terdapat pontensi konflik kepentingan dengan penelitian, kepenulisan (authorship) dan atau publikasi penelitian ini.

\section{Daftar Pustaka}

1. Kementerian Kesehatan Republik Indonesia. Pedoman manajemen pelayanan keluarga berencana. Jakarta: Kementerian Kesehatan Republik Indonesia; 2014.

2. Visser J, Snel M, Van Vliet HA. Hormonal versus non-hormonal contraceptives in women with diabetes mellitus type 1 and 2. Cochrane Database Syst Rev. 2013;3: CD003990. doi: 10.1002/14651858.CD0 03990.pub4.

3. Mason JM, Chalmers JR, Godec T, Nunn AJ, Kirtschig G, Wojnarowska F, et al. Doxycycline compared with prednisolone therapy for patients with bullous pemphigoid: Cost-effectiveness analysis of the BLISTER trial. Br J Dermatol. 2018; 178(2):415-23. doi: 10.1111/b jd.16006.

4. Faridah N, Machlaurin A, Prihwanto BS. Analisis efektivitas biaya penggunaan antibiotik terhadap pasien sepsis pediatrik di rawat inap RSD dr. Soebandi Kabupaten Jember pada tahun 2014. E-Jurnal Pustaka Kesehatan. 2016;4(2):255-62.

5. Kementerian Kesehatan Republik Indonesia. Riset kesehatan dasar 2017. Jakarta: Kementerian Kesehatan Republik Indonesia; 2018.

6. Hoshi SL, Seposo X, Okubo I, Kondo M. Cost-effectiveness analysis of pertussis vaccination during pregnancy in Japan. Vaccine. 2018;36(34):5133-40. doi: 10.1 016/j.vaccine.2018.07.026.

7. Nguyen E, Craig IC, Christine GK, Erin RW. Ranozaline in patients with type 2 diabetes and chronic angina: A costeffectiveness analysis and assessment of health-related quality-of-life. Int $\mathrm{J}$ Cardiol. 2018;273:34-8. doi: 10.1016/j.ij card.2018.09.060.

8. Cho SK, Hay JW, Barzi A. Cost-effectiveness analysis of regorafenib and TAS-102 in refractory metastatic colorectal cancer in the United States. Clin Colorectal Cancer. 2018;17(4):e751-61. doi: 10.1016/j.clcc. 2018.08.003.

9. Ikeme S, Weltert L, Lewis KM, Bothma G, Cianciulli D, Pay N, et al. Costeffectiveness analysis of a sealing hemostat patch (HEMOPATCH) vs standard of care in cardiac surgery. J Med Econ. 2018;21(3):273-81. doi: 10.1080/1 3696998.2017 .1400977

10. Tromp N, Siregar A, Leuwol B, Komarudin D, van der Ven A, van Crevel $\mathrm{R}$, et al. Cost-effectiveness of scaling up voluntary counselling and testing in West-Java, Indonesia. Acta Med Indones. 2013;45(1):17-25.

11. Bellows BK, Tak CR, Sanders JN, Turok DK, Schwarz EB. Cost-effectiveness of 
emergency contraception options over 1 year. Am J Obstet Gynecol. 2018;218(5): 508.e1-e9. doi: 10.1016/j.ajog.2018.01.0 25.

12. Kementerian Kesehatan Republik Indonesia. Riset kesehatan dasar 2016. Jakarta: Kementerian Kesehatan Republik Indonesia; 2017.

13. Veisi F, Zangeneh M. Comparison of two different injectable contraceptive methods: Depo-medroxy progesterone acetate (DMPA) and cyclofem. J Family Reprod Health. 2013; 7(3):109-113.

14. Lipetz C, Phillips CJ, Fleming CF. The costeffectiveness of a long-acting reversible contraceptive (Implanon) relative to oral contraception in a community setting. Contraception. 2009;79(4):304-9. doi: 10. 1016/j.contraception.2008.11.003.

15. Trussell J, Lalla AM, Doan QV, Reyes E, Pinto L, Gricar J. Cost effectiveness of contraceptives in the United States. Contraception. 2009;79(1):5-14. doi: 10. 1016/j.contraception.2008.08.003.

16. Agostini A, Godard C, Laurendeau C, Benmahmoud A, Lafuma A, Doz M, et al. Effectiveness and cost of contraception in France (FACET study): A cohort study from the French National Healthcare Insurance Database. Eur J Obstet Gynecol Reprod Biol. 2018;229:137-43. doi: 10.1 016/j.ejogrb.2018.08.007.

17. Sharlip ID, Belker AM, Honig S, Labrecque M, Marmar JL, Ross LS, et al. Vasectomy: AUA guideline. J Urol. 2012;188(6):2482-91. doi: 10.1016/j.jur o.2012.09.080.

18. D'Anna LH, Korosteleva O, Warner L, Douglas J, Paul S, Metcalf C, et al. Factors associated with condom use problems during vaginal sex with main and non-main partners. Sex Transm Dis. 2012;39(9):687-93. doi: 10.1097/OLQ.0 b013e31825ef325

19. Bulsei J, Darlington M, Durand-Zaleski I, Azizi M; DENERHTN Study Group. How to perform a cost-effectiveness analysis with surrogate endpoint: Renal denervation in patients with resistant hypertension (DENERHTN) trial as an example. Blood Press. 2018;27(2):66-72. doi: 10.1080/08037051.2017.1394160.

20. Mavranezouli I. Health economics of contraception. Best Pract Res Clin Obstet Gynaecol. 2009;23(2):187-98. doi: 10.10 16/j.bpobgyn.2008.11.007.

21. Mustafa N. Cost-effectiveness analysis: Educational interventions that reduce the incidence of HIV/AIDS infection in Kenyan teenagers. Int J Educ Dev. 2018;62(C):264-9. doi: 10.1016/j.ijedud ev.2018.06.001

22. Schmid R. The cost-effectiveness of emergency hormonal contraception with ulipristal acetate versus levonorgestrel for minors in France. PLoS One. 2015; 10(9):e0138990. doi: 10.1371/journal.po ne.0138990.

23. World Health Organization. Selected practice recommendations for contraceptive use. Jenewa: World Health Organization; 2004.

(C) 2019 Khoiriyah et al. The full terms of this license incorporate the Creative Common Attribution-Non Commercial License (https://creative commons.org/licenses/by-nc/4.0/). By accessing the work you hereby accept the terms. Non-commercial use of the work are permitted without any further permission, provided the work is properly attributed. 